\title{
Role of MiR-155 Signal Pathway in Regulating Podocyte Injury Induced by TGF- $\beta 1$
}

\author{
Xu Lin Xintng Zhen Haiting Huang Haohao Wu Yanwu You Pengwei Guo \\ Xiangjun Gu Fafen Yang
}

Department of Nephrology, The Affiliated Hospital of Youjiang Medical University for Nationalities, Baise, China

\author{
Key Words \\ Podocytes $\cdot$ TGF- $\beta 1 \cdot$ MiR-155 - Nephrin • Desmin • Caspase 9
}

\begin{abstract}
Background/Aims: Transforming growth factor beta 1 (TGF- $\beta 1$ ) plays a critical role in the pathogenesis of glomerulosclerosis. The purpose of this study was to examine the effects of inhibition of miR-155 on podocyte injury induced by TGF- $\beta 1$ and to determine further molecular mediators involved in the effects of miR-155. Methods: Conditionally immortalized podocytes were cultured in vitro and they were divided into four groups: control; TGF- $\beta 1$ treatment; TGF- $\beta 1$ with miR-155 knockdown [using antisense oligonucleotides against miR155 (ASO-miR-155)] and TGF- $\beta 1$ with negative control antisense oligonucleotides (ASO-NC). Real time RT-PCR and Western blot analysis were employed to determine the mRNA and protein expression of nephrin, desmin and caspase-9, respectively. Flow cytometry was used to examine the apoptotic rate of podocytes and DAPI fluorescent staining was used to determine apoptotic morphology. In addition, we examined the levels of miR-155, TGF- $\beta 1$, nephrin, desmin and caspase- 9 in glomerular tissues of nephropathy induced by intravenous injections of adriamycin in rats. Results: mRNA and protein expression of desmin and caspase- 9 was increased in cultured TGF- $\beta 1$-treated podocytes, whereas nephrin was decreased as compared with the control group. Importantly, miR-155 knockdown significantly attenuated upregulation of desmin and caspase-9, and alleviated impairment of nephrin induced by TGF- $\beta 1$. Moreover, the number of apoptotic podocytes was increased after exposure to TGF- $\beta 1$ and this was alleviated after miR-155 knockdown. Knocking down miR-155 also decreased an apoptosis rate of TGF- $\beta 1$-treated podocytes. Note that negative control antisense oligonucleotides failed to alter an increase of the apoptosis rate in TGF- $\beta 1$-treated podocytes. Consistent with in vitro results, expression of miR-155, TGF- $\beta 1$, desmin and caspase- 9 was increased and nephrin was decreased in glomerular tissues with nephropathy in vivo experiments. Conclusions: TGF- $\beta 1$ impairs the protein expression of nephrin and amplifies the protein expression of desmin and caspase -9 via miR-155 signal pathway. Inhibition of miR-155 alleviates these changes in podocytes-treated with TGF- $\beta 1$ and attenuated apoptosis of podocytes. Our data suggest
\end{abstract}


that miR-155 plays a role in mediating TGF- $\beta 1$-induced podocyte injury via nephrin, desmin and caspase-9. Results of the current study also indicate that blocking miR-155 signal has a protective effect on podocyte injury. Targeting one or more of these signaling molecules may present new opportunities for treatment and management of podocyte injury observed in glomerulosclerosis.

\section{Introduction}

A number of distinct changes such as glomerulosclerosis, interstitial fibrosis, tubular atrophy, progressive peritubular capillary loss and persistent inflammation appear in patients with renal fibrosis $[1,2]$. Therapy for renal fibrosis remains somewhat problematic as the underlying mechanisms of these diseases are lacking. Animal models offer a better opportunity to study the mechanisms at cellular and molecular levels [3]. Among several models, nephropathy induced by intravenous injections of adriamycin (ADR) in rats has been widely used to study focal segmental glomerulosclerosis (FSGS) that is observed in patients, and this model is considered as an analogue of human FSGS $[1,3,4]$.

Transforming growth factor beta 1 (TGF- $\beta 1$ ) is a polypeptide member of the transforming growth factor beta superfamily of cytokines $[5,6]$. It is a secreted protein that performs many cellular functions including the control of cell growth, proliferation and differentiation; and dysregulation of TGF- $\beta$ activation and signaling results in cell apoptosis. [7-9]. Notably, TGF- $\beta 1$ is one of important cytokines in renal tissues in contribution to the pathogenesis of glomerulonephritis [10]. Overexpression of TGF- $\beta 1$ has been revealed in kidney diseases of human and animal models and TGF- $\beta 1$ produced in glomerulus plays a role in regulating multiple pathophysiological functions in the process of the diseases [10-12]. For instance, TGF- $\beta 1$ stimulates expansion of extracellular matrix (ECM) and exacerbates podocyte injury including changes of cell morphology, detachment from glomerular basement membrane and apoptosis [13-15]. Prior studies have further demonstrated a number of intracellular signal pathways [i.e., mitogen-activated protein kinase (MAPK), extracellular signal-regulated kinase (ERK), phosphatidyl inositol- 3-kinase (PI3K) and nuclear factor- $\kappa B(N F-\kappa B)$ etc.] in involvement of podocyte injury induced by TGF- $\beta 1$ [16-18]. It should be noted that using a rat model with systemic injection of ADR, our recent study consistently observed that the higher protein expression levels of TGF- $\beta 1$ and apoptotic Caspase-9 in glomerular tissues, suggesting the role of TGF- $\beta 1$ in the process of FSGS [19]. Nonetheless, it is significant to further determine the mechanisms leading to FSGS in renal diseases by using ADR-induced nephropathy.

MiR-155 is a microRNA that in humans is encoded by the MIR155 host gene or MIR155HG [20]. It is known that MiR-155 plays a role in various physiological and pathological processes [20-23]. Inflammatory responses to triggers such as pro-inflammatory TNF- $\alpha$ include macrophages with components containing miR-155. MiR-155 contributes to chronic inflammation by increasing the proliferative response of $\mathrm{T}(\mathrm{H})$ cells through the downregulation of CTLA4 [24]. In autoimmune disorders such as rheumatoid arthritis, a higher expression of miR-155 is presented in patients' tissues and synovial fibroblasts [20]. In multiple sclerosis, increased expression of miR-155 has been found in peripheral and central nervous system-resident myeloid cells, including circulating blood monocytes and activated microglia [25]. It was also reported that miR-155 is implicated in inflammation and overexpression of miR-155 leads to chronic inflammatory state in human [23].

Additionally, miR-155 is specifically localized in renal tissues and engaged in the pathogenesis of renal symptoms in patients with glomerulonephritis [26, 27]. Additional studies further show a linkage of miR-155 to tissue injuries observed in renal diseases [2831]. Our recent work has shown that nephrin is decreased whereas desmin is upregulated in podocyte cultured with TGF- $\beta 1$ [19], indicating that nephrin and desmin are involved in TGF$\beta 1$-induced podocyte injuries. Notably, our prior study has also provided evidence that miR155 deficiency (using miR-155 $7^{-}$mice) promotes nephrin expression and attenuates renal 
Lin et al.: MiR-155 Signaling and Podocyte Injury

damage in hyperglycemia-induced nephropathy in vivo experiments of mice model [26]. Nonetheless, the underlying mechanisms by which miR-155 regulates glomerular podocyte injuries induced by TGF- $\beta 1$ remain to be determined. Accordingly, the purpose of this study was to determine the role played by miR-155 in modulating podocyte injury induced by TGF- $\beta 1$. We hypothesized that inhibition of miR-155 signal using antisense oligonucleotides against miR-155 alleviates abnormal expression of nephrin and desmin and thereby improves podocyte injuries induced by TGF- $\beta 1$. Moreover, in order to better understand the role of miR-155 we performed in vivo experiments and examined expression of miR-155, TGF- $\beta 1$, nephrin, desmin and Caspase-9 in glomerular tissues of rats with injection of ADR. We hypothesized that ADR amplifies miR-155, TGF- $\beta 1$, desmin and Caspase- 9 and impairs nephrin, and this is accompanied with increases of urinary protein concentrations.

\section{Materials and Methods}

\section{Podocyte culture and treatment}

Conditionally immortalized mouse podocyte cells were maintained at $33^{\circ} \mathrm{C}$ for proliferation in RPMI 1640 containing $10 \%$ fetal bovine serum (Gibco) and $10 \mathrm{U} / \mathrm{ml}$ of recombinant mouse $\gamma$-interferon (Cat \# PMC4031, Invitrogen). They were then moved to $37^{\circ} \mathrm{C}$ for differentiation and cultured without $\gamma$-interferon. When they grew to about $80 \%$ confluence, podocytes were treated with $6 \mathrm{ng} / \mathrm{ml}$ of TGF- $\beta 1$ (Cat \# 14-834262, Invitrogen) in serum-free medium and incubated with antisense oligonucleotides against miR-155 (ASOmiR-155: 5'ACCCCUAUCAAGAUUAGCAUUAA 3') and negative control antisense oligonucleotides (ASO-NC: 5'CAGUACUUUUGUGUAGUACAA3'; ASO-miR-155 and ASO-NC were synthesized by Shanghai GenePharma Co., Shanghai, China) according to the provided protocol. Then, they were moved to $37^{\circ} \mathrm{C}$ and treated with 6 $\mathrm{ng} / \mathrm{ml}$ of TGF- $\beta 1$ for 24-72 hours. Thus, the cultured podocytes were divided as control; TGF- $\beta 1$-treatment; TGF- $\beta 1$-treatment with ASO-miR-155 and TGF- $\beta 1$-treatment with ASO-NC.

\section{Real-time PCR}

RT-PCR was performed using the TaqmanW Universal PCR Master Mix (Applied Biosys.). This mix contains AmpliTaq GoldW DNA Polymerase, AmpEraseW UNG, ROX passive reference, buffer and dNTPs, as well as gene-specific primers for the mRNA amplification of the following genes: nephrin, desmin, caspase -9 and miR-155. In addition, $18 \mathrm{~s}$ rRNA (TaqmanW PDAR) was used as an endogenous control to correct for variations in the samples. RT-PCR was performed in duplicate in 96 -well plates containing $2 \mu \mathrm{L}$ of cDNA. The thermal conditions of the cycles were $50^{\circ} \mathrm{C}$ for 2 minutes, $60^{\circ} \mathrm{C}$ for 30 minutes, and $95^{\circ} \mathrm{C}$ for 5 minutes and this was followed by 40 cycles at $94^{\circ} \mathrm{C}$ for 20 seconds and $62^{\circ} \mathrm{C}$ for 60 seconds. The data were collected in the ABI PRISM SDS 7000 thermal cycler. Relative quantification of target gene expression was performed using the $2^{-\Delta \Delta \mathrm{Ct}}$ comparative method and the threshold cycle value was defined by the point at which there was a statistically significant detectable increase in fluorescence.

Determination of apoptosis in cultured podocytes

Annexin V-FITC Apoptosis Detection Kit (BD Biosciences) was applied to evaluate podocyte injury. Briefly, podocytes were harvested and washed twice with pre-cold phosphate-buffered saline (PBS). $1 \mathrm{x}$ $10^{6}$ cells were re-suspended in $1 \mu \mathrm{g} / \mathrm{ml}$ FITC-Annexin $\mathrm{V}$ for $30 \mathrm{~min}$ at $4^{\circ} \mathrm{C}$ followed by adding $5 \mu \mathrm{l}$ of 50 $\mu \mathrm{g} / \mathrm{ml}$ propidium iodide immediately prior to detection with flow cytometry (FACScan). Cells that stained positive for FITC Annexin V and negative for propidium iodide were considered as undergoing apoptosis. Cells were characterized as viable, necrotic, early apoptotic or late apoptotic according to standard staining characteristics. The apoptosis rate was measured as the fraction of cells in early and late apoptosis. The measurement was repeated 3 times for each group and the mean value was obtained by averaging these data to indicate apoptosis rate.

In addition, DAPI fluorescent staining was also used to assess apoptosis of podocytes. In this approach, podocytes were cultured and treated for 72 hours and then $10 \mu \mathrm{g} / \mathrm{ml}$ of DAPI in PBS was added at $37^{\circ} \mathrm{C}$ for 15 min. DAPI-positive cells were observed using a Nikon Eclipse 80i fluorescence microscope and images were taken using the Nis-Elements software (Nikon, Co.).

\section{KARGER}




\section{Cellular Physiology Cell Physiol Biochem 2017;42:1469-1480 \\ \begin{tabular}{l|l} 
and Biochemistry Published 10.1159/000479211 2017 & $\begin{array}{l}\text { (c) 2017 The Author(s). Published by S. Karger AG, Basel } \\
\text { www.karger.com/cpb }\end{array}$ \\
\hline
\end{tabular}}

Lin et al.: MiR-155 Signaling and Podocyte Injury

Whole animal experiments

All experimental procedures were in accordance with the guidelines of the International Association for the Study of Pain and were approved by the Animal Research Committee of Youjiang Medical University for Nationalities. Male Sprague-Dawley rats weighing 200-250 g were used in this study. A rat model of nephropathy was induced by intravenous injections of ADR $(4 \mathrm{mg} / \mathrm{kg}$ at the first week and $2 \mathrm{mg} / \mathrm{kg}$ at the fourth week) after the right kidney was extirpated as described previously [32]. At the end of the sixth week rats were sacrificed and the kidney was removed and glomeruli were isolated using a sieving procedure for the Western blot analysis to determine the protein expression of TGF- $\beta 1$, nephrin, desmin and caspase- 9 , and for RT-PCR to examine miR-155 expression. Age- and body weight-matched rats with sham-operation and saline injection were used as controls. Urine samples were collected before the surgery and at the end of each week. Then, in order to determine the effectiveness of ADR injection inducing renal injuries urinary protein concentrations were determined by colorimetric assay (Bio-Rad) using bovine serum albumin (BSA) as the standard. Proteinuria was confirmed by urinary protein concentrations in samples.

\section{Western blotting analysis}

Total protein in glomerular tissue and cells was extracted by homogenizing sample in ice-cold radioimmunoprecipitation assay buffer with protease inhibitor cocktail kit (Roche). The lysates were centrifuged and the supernatants were collected for measurements of protein concentrations using a bicinchoninic acid assay reagent kit. Fifty microgram of total protein was loaded to run $7.5 \%$ or $10 \%$ sodium dodecyl sulfate-polyacrylamide gel electrophoresis (SDS-PAGE), and the protein was transferred to nitrocellulose membranes (GE Healthcare Biosci). Then, the membranes were incubated for 30 minutes in $5 \%$ low-fat milk prepared with Tris-buffered saline containing $0.05 \%$ Tween-20 (TTBS). Subsequently, the membranes were incubated with primary antibodies (diluted at 1:200-1:500) as the rabbit anti-TGF- $\beta 1$ (Cat\# ab92486, Abcam Co), anti-nephrin (Cat\# ab58968, Abcam Co), anti-desmin (Cat\# ab15200, Abcam Co) and anti-caspase-9 (Cat\# ab52298, Abcam Co). After being fully washed, the membrane was incubated with horseradish peroxidase-linked anti-rabbit secondary antibody (1:250, sc-2357, Santa Cruz Biotech) and visualized for immunoreactivity. The membrane was also processed to detect $\beta$-actin or GADPH by their respective antibodies (anti- $\beta$-actin, Cat\# ab8227, Abcam Co; and anti-GADPH, Cat\# ab37168, Abcam Co) for equal loading. The bands recognized by the primary antibody were visualized and the optical densities of protein bands were analyzed using the ImageJ software. Then, values for densities of immunoreactive bands/ $\beta$-actin or GADPH band from the same lane were determined. Each of the values was then normalized to a control sample.

\section{Statistical analysis}

All data were analyzed using a two-way repeated-measures analysis of variance. Values were presented as means \pm standard error of mean (SEM). For all analyses, differences were considered significant at $P<$ 0.05. All statistical analyses were performed by using SPSS for Windows version 17.0 (SPSS, USA).

\section{Results}

\section{MiR-155 knockdown}

We first observed that the cultured podocytes used in our present experiments appeared in a fusiform and/or polygonal shape with a clear outline. In addition, expression of GFP on podocytes was increased 24, 48 and 72 hours following TGF- $\beta 1$ transfection and it appeared slightly greater in 72 hours post-transfection than that in 24 and 48 hours post-transfection (Fig. 1A). Thus, 72 hours of post-transfection was used in this study in the following experiments examining mRNA and protein expression of nephrin, desmin and caspase-9. The effectiveness of miR-155 knockdown was also confirmed. Downregulation of expression of miR-155 was observed in podocytes in which ASO-miR-155 was transfected as compared with the control group and negative transfection group (Fig. 1B; $P<0.05$ ).

Effects of miR-155 knockdown on expression of nephrin, desmin and caspase-9

As compared with the control group, mRNA and protein expression of desmin and caspase-9 was increased in cultured TGF- $\beta 1$-treated podocytes (Fig. $2 \mathrm{~A} \& \mathrm{~B} ; P<0.05$ ), 
Fig. 1. (A) greater expression of GFP on podocytes appears in 72 hours post-transfection of TGF- $\beta 1$ vs. 24 and 48 hours post-transfection. Scale bar: $100 \mu \mathrm{m}$. (B) showing decrease of mRNA expression of miR155 observed in podocytes with transfection of ASO-miR-155. ${ }^{*} \mathrm{P}<0.05$ vs. control group and negative transfection group.
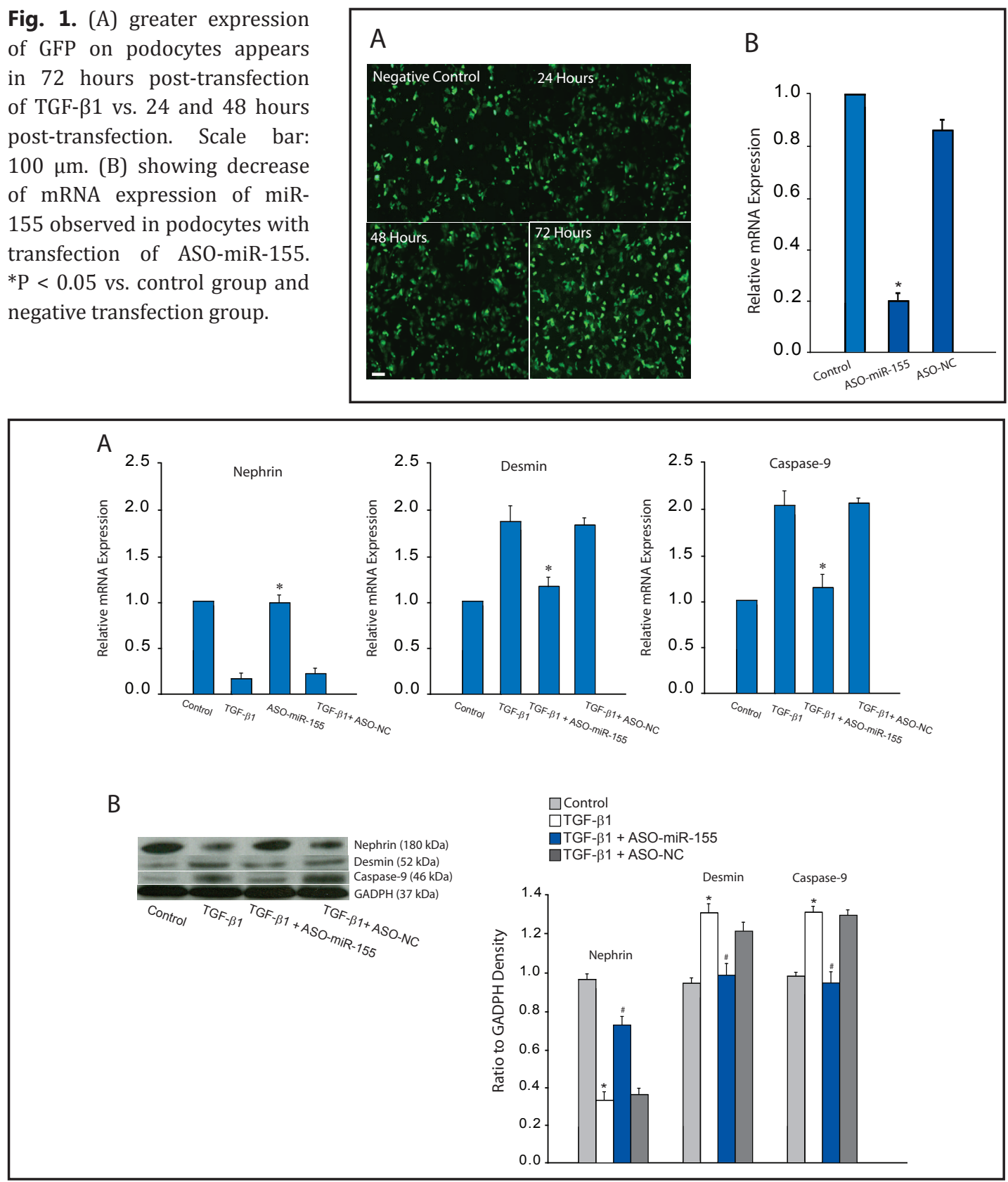

Fig. 2. (A) The expression of mRNA of nephrin was decreased whereas mRNA of desmin and caspase- 9 was increased in cultured TGF- $\beta 1$-treated podocytes for 72 hours. MiR-155 knockdown significantly restored these changes. ${ }^{*} \mathrm{P}<0.05$ vs. $\beta 1$-treated podocytes without miR-155 knockdown and $\beta 1$-treated podocytes with negative control. (B) Typical bands and averaged data showing the protein expression levels of nephrin were decreased and desmin and caspase- 9 were increased in cultured TGF- $\beta 1$-treated podocytes for 72 hours. As miR-155 was knocked down these changes were diminished. ${ }^{*} \mathrm{P}<0.05$ vs. control. \#P $<0.05$ vs. $\beta 1$-treated podocytes without miR-155 knockdown and $\beta 1$-treated podocytes with negative control.

whereas mRNA and protein expression of nephrin was decreased $(P<0.05)$. In addition, miR-155 knockdown significantly attenuated amplifications in desmin and caspase- 9 as well as a reduction in nephrin induced by TGF- $\beta 1$ treatment (Fig. 2A\&B). 

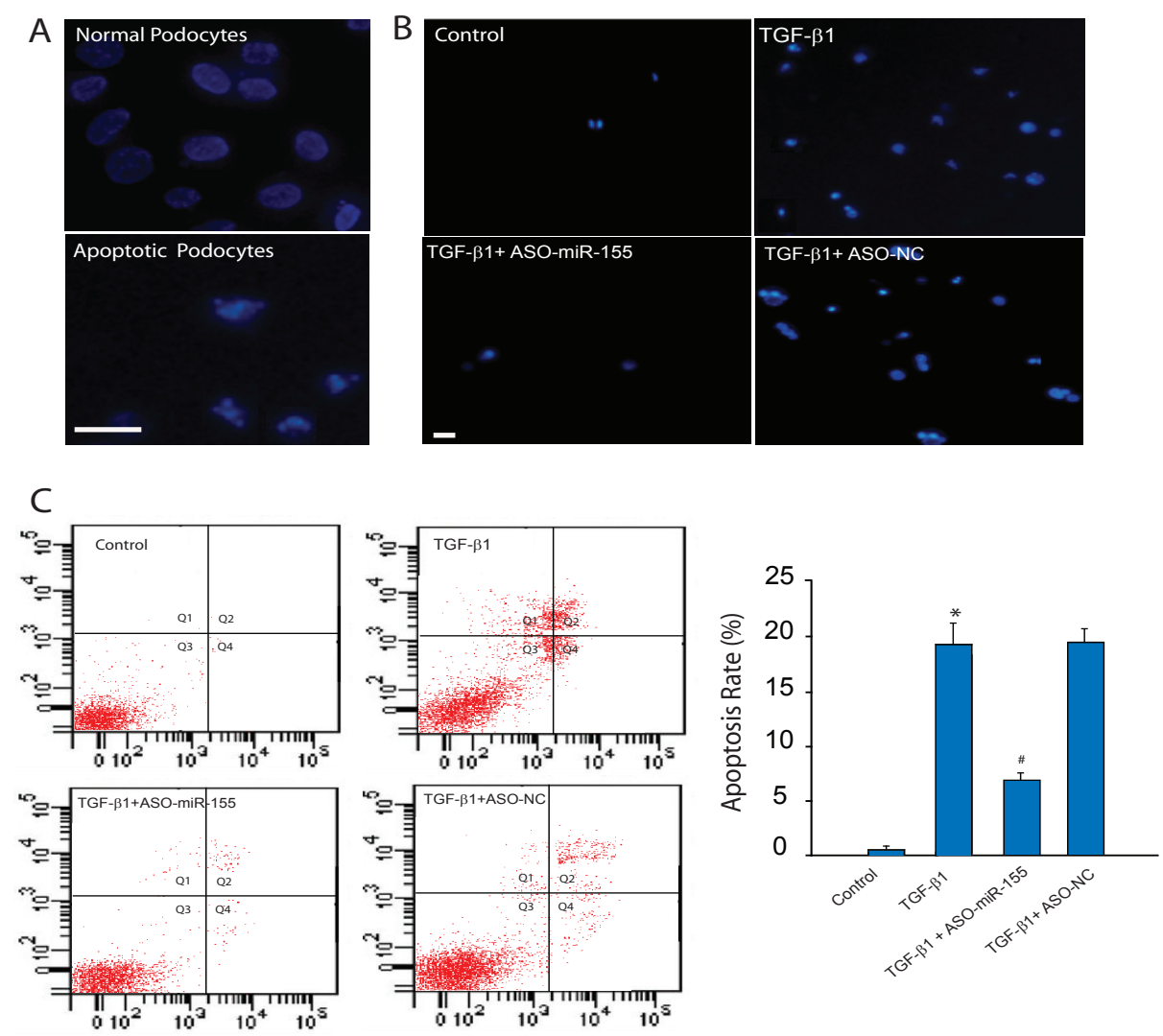

Fig. 3. (A) Morphologic features of nucleus are presented in normal podocytes (top: consistent size of nucleus) and apoptotic podocytes (bottom: different size of broken nucleus). The photography was taken by a microscope under $20 \mathrm{x}$ magnification. (B) The number of apoptotic podocytes was increased after exposure to TGF- $\beta 1$ as compared with control and this was attenuated after miR-155 knockdown. Effects of miR-155 were not observed in negative control group. (C) MiR-155 knockdown decreased the apoptosis rate of TGF- $\beta 1$-treated podocytes as compared with the rate without knockdown and negative control. Negative transfection control did not alter an increase of apoptosis rate in TGF- $\beta 1$-treated podocytes. ${ }^{*} \mathrm{P}<0.05$ vs. control group; and \# P < 0.05 vs. TGF- $\beta 1$ treatment and miR-155 negative control. Scale bar: $20 \mu \mathrm{m}$ (in A\&B).

\section{Effects of miR-155 knockdown on apoptosis of podocyte}

Figure $3 \mathrm{~A}$ illustrates that morphologic features were observed with a consistent size of nucleus in normal podocytes vs. different size of broken nucleus in apoptotic podocytes. Results also show that the number of apoptotic podocytes was increased after exposure to TGF- $\beta 1$ for 72 hours and this was attenuated after miR-155 knockdown (Fig. 3B). In addition, MiR-155 knockdown decreased the apoptosis rate of TGF- $\beta 1$-treated podocytes (Fig. 3C; $7 \pm$ $1 \%$ after miR-155 knockdown $v s .19 \pm 2 \%$ without knockdown, $P<0.05$ ). Note that negative transfection control failed to alter an increase of apoptosis rate in TGF- $\beta 1$-treated podocytes.

\section{In vivo experiments using a rat model of ADR nephropathy (ADRN)}

In order to determine engagement of miR-155 in the pathophysiological processes of ADRN, we further examined expressions of TGF- $\beta 1$, miR-155, nephrin, desmin and caspase- 9 in situ renal tissues of control rats and ADRN rats with 6 weeks of ADR injection. Figure 4A shows that mRNA of miR-155 was increased in the renal tissues of ADRN rats $(P<0.05$ $v s$. control rats). This figure also shows that protein expression levels of TGF- $\beta 1$, desmin and caspase- 9 were upregulated in ADRN rats $(P<0.05 v s$. control rats for all the proteins) whereas nephrin was decreased in ADRN rats $(P<0.05$ vs. control rats $)$ as compared with 


\section{Cellular Physiology Cell Physiol Biochem 2017;42:1469-1480 \begin{tabular}{ll|l} 
DOI: 10.1159/000479211 & O 2017 The Author(s). Published by S. Karger AG, Basel \\
www.karger.com/cpb
\end{tabular} \\ Lin et al.: MiR-155 Signaling and Podocyte Injury}

Fig. 4. (A) Expression of miR-155 mRNA (left panel) and protein expression of TGF- $\beta 1$, nephrin, desmin and caspase- 9 in the renal tissues (right panels: typical bands on the top and averaged data on the bottom). ${ }^{*} \mathrm{P}<0.05$ vs. control rats. (B) Effects of intravenous injection of ADR on urinary protein. The levels of urinary protein began to increase 2 weeks after ADR injection and reached to a high level at the sixth week. This confirmed the effectiveness of ADR in induction of renal injuries. ${ }^{*} \mathrm{P}<0.05$ vs. control rats. The number of animals $=8$ in each of groups (control and ADR injection).

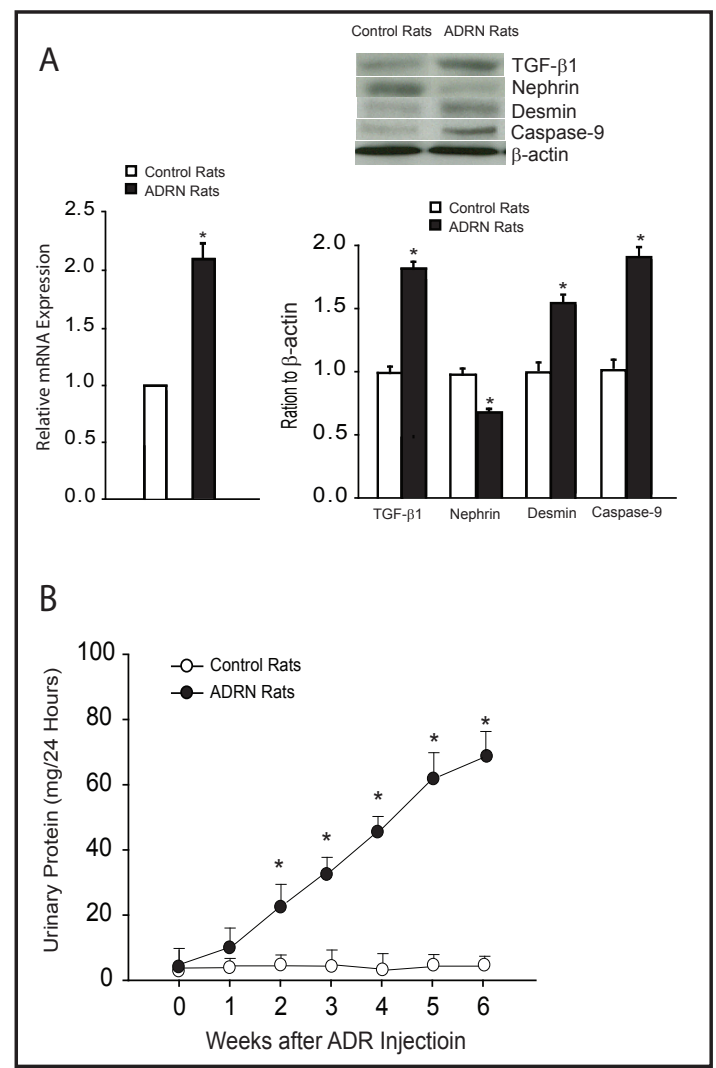

control animals. Figure 4B further confirmed that the levels of urinary protein began to significantly increase 2 weeks after ADR injection and reached to a higher level at the sixth week. This result confirmed that ADR injection was effective in induction of renal injuries.

\section{Discussion}

Human and animal studies have shown the role played by miR-155 in renal injuries including nephropathy [28-31, 33-35]. For example, miR-155 expression is substantially increased in the renal tissues of rats with ischemia/reperfusion injury and in the cultured human renal proximal tubular cell line HK-2 subjected to hypoxia and re-oxygenation [31]. Also, upregulation of miR-155 can promote HK2 cell pyroptosis (indicated by increasing pyroptosis-related proteins such as caspase-1, caspase-11, IL-1 $\beta$ and IL-18) induced by hypoxia and re-oxygenation injury, whereas knockdown of miR-155 attenuates this process [31]. In addition, propofol, an agent effectively attenuating renal injury, inhibits TGF- $\beta 1$ expression consequently alleviating epithelial-mesenchymal transition and kidney fibrosis by regulating miR-155 levels [30]. In renal samples of patients with diabetic nephropathy, expression of miR-155 is increased more than fivefold as compared with the controls, and the miR-155 expression is closely correlated with the serum creatinine levels [28]. During the induction and progression of the disease in type 1 and type 2 diabetic nephropathy rat models, miR-155 is also increased gradually [28]. This study further showed that high glucose induces the over-expression of miR-155 in human renal glomerular endothelial cells, which, in turn, increases TNF- $\alpha$, TGF- $\beta 1$, and NF- $\kappa$ B expression [28]. The findings of this prior study [28] indicate that the increased expression of miR-155 in the diabetic nephropathy patients and in the experimental animal models with diabetic nephropathy contributes to inflammation-mediated glomerular endothelial injury.

Our recent work has shown that nephrin is decreased whereas desmin is upregulated in injured podocyte induced by TGF- $\beta 1$ [19], indicating that nephrin and desmin are 
involved in TGF- $\beta 1$-induced podocyte injuries. Additionally, miR-155 is specifically localized in renal tissues and engaged in the pathogenesis of renal symptoms in patients with glomerulonephritis [26, 27]. Our prior study has also provided evidence that miR155 deficiency (using miR-155\% mice) promotes nephrin expression and attenuates renal damage in hyperglycemia-induced nephropathy in vivo experiments of mice model [26]. Nonetheless, the underlying mechanisms by which miR-155 regulates glomerular podocyte injuries induced by TGF- $\beta 1$ remain to be determined. In the present study, we performed a series of in vitro experiments in order to determine the role played by miR-155 in mediating TGF- $\beta 1$-induced podocyte injury. Our data showed that in podocytes treated with TGF- $\beta 1$, impaired nephrin is largely recovered and upregulated desmin and caspase- 9 are significantly attenuated following miR-155 knockdown. Moreover, an apoptosis rate of TGF- $\beta 1$-treated podocytes is decreased following miR-155 knockdown.

ADR-induced nephropathy model has been considered as an analogue of human FSGS [4]. Prior studies suggest that TGF- $\beta 1 /$ Smad signaling activity plays a key role in the accumulation of ECM in ADRN [36-38]. In the present study using the same rat model, our in vivo experiments demonstrated that the mRNA expression of miR-155 and protein expression of TGF- $\beta 1$, desmin and caspase- 9 are upregulated, whereas nephrin is decreased in ADRN rats. This is consistent with the results observed in the cultured podocytes transfected with TGF- $\beta 1$. i.e., desmin and caspase- 9 are increased and nephrin is decreased. Overall, our data suggest that molecular mediators such as desmin, caspase- 9 and nephrin are engaged in the role of miR-155 signal in mediating podocyte injury induced by TGF- $\beta 1$. Nonetheless, there is a study limitation that we did not present changes of those molecular mediators in glomeruli using the whole tissue morphology.

In general, podocytes are the target of injury in chronic glomerular diseases. In these diseases, TGF- $\beta 1$ is secreted by mesangial cells and stored in ECM as latent complexes, and then transported to podocyte surface [39]. On podocytes, TGF- $\beta 1$ binds to its receptor and activates its downstream signaling pathways including Smad, MAPK, ERK and PI3K to modulate the expression of its target genes $[11,16,18]$. TGF- $\beta 1$ protein increases in these podocytes with the cellular lesions of glomerulonephritis $[11,12]$. It has been reported that TGF- $\beta 1$ reduces podocyte adhesion through $\alpha 3 \beta 1$ integrin downregulation and thus induces podocyte apoptosis [40].

In addition, podocytes undergo apoptosis at early stages in the course of progressive glomerulonephritis in TGF- $\beta 1$ transgenic mice [41, 42]. A prior study has demonstrated that local production of TGF- $\beta 1$ leads to the progression of podocyte damage [16]. In the cultured murine podocytes, it was also reported that TGF- $\beta 1$ induces podocyte apoptosis [43]. Interestingly, miR-155 is induced in TGF- $\beta 1$-treated podocyte, implying that miR155 is likely involved in TGF- $\beta 1$-induced podocyte injury. Our present study provided strong evidence that miR-155 knockdown attenuates the apoptosis rate in TGF- $\beta 1$-treated podocyte, which also is linked to impaired nephrin and upregulated desmin and caspase-9. These data suggest that these molecular protein mediators are necessary in involvement of miR-155 signal engaged in podocyte damage induced by TGF- $\beta$.

Nephrin is a transmembrane protein that is a structural component of the slit diaphragm and necessary for the proper functioning of the renal filtration barrier [44-46]. The renal filtration barrier consists of fenestrated endothelial cells, the glomerular basement membrane, and the podocytes of epithelial cells [44-46]. They are present on the tips of the podocytes and maintain the normal relationship between the basement membrane and the podocytes of the epithelial cells. Nephrin regulates a number of pathways in the podocyte, suppresses cell death and apparently forms a complex with podocin [44]. Thus, depletion of nephrin and podocin is associated with degradation of the foot process [44]. A defect in the gene for nephrin, NPHS1, is associated with congenital nephrotic syndrome of the Finnish type and causes massive amounts of protein to be leaked into the urine or proteinuria [47]. Nephrin has also been used as a biomarker for kidney diseases [48]. Many factors inducing podocyte injury increase the levels of nephrin and direct evidence further shows that nephrin is very important in improving podocyte apoptosis of nephropathy [49-52]. In 
our present study, we found that nephrin is impaired in TGF- $\beta 1$-treated cultured podocytes. Inhibition of miR-155 signal can restore the expression levels of its protein, indicating the crucial role played by miR-155 in mediating podocyte injury induced by TGF- $\beta 1$, which occurs in glomerulonephritis.

Desmin is a type III intermediate filament that integrates the sarcolemma, $\mathrm{Z}$ disk and nuclear membrane in sarcomeresand regulates sarcomere architecture [53]. In adult muscle, desmin forms a scaffold around the Z-disk of the sarcomere and connects the Z-disk to the subsarcolemmal cytoskeleton [54]. It links to the myofibrils laterally by connecting the Z-disks [53]. Through its connection to the sarcomere, desmin connects the contractile apparatus to the cell nucleus, mitochondria, and post-synaptic areas of motor endplates [53]. These connections maintain the structural and mechanical integrity of the cell during contraction while they also help in force transmission and longitudinal load bearing $[54,55]$. Upregulated desmin expression is a defense mechanism in maintaining normal sarcomere alignment amidst disease pathogenesis [56]. There is evidence that desmin also connects the sarcomere to the ECM through desmosomes which is likely important in signaling between the ECM and the sarcomere in regulating tissue contraction and movement [55]. Of note, prior studies suggest that desmin is a sensitive marker of podocyte injury [57]. Also, desmin mRNA and protein are increased in cultured mouse podocytes and in vivo study it has been reported that desmin is increased in damaged mouse podocytes by insults of numerous kidney disorders, suggesting that desmin is involved in podocyte injury [58, 59]. Moreover, recovering protein levels of desmin expression play a protective role in regulating injured podocytes [60-62]. Consistent with this concept, in the current study we found that desmin is exaggerated in TGF- $\beta 1$-treated cultured podocytes and inhibition of miR-155 alleviates exacerbated expression of desmin.

A study limitation should be acknowledged in this report. In the present study, we compared expression of GFP on podocytes at the different course (i.e., 24, 48 and 72 hours following TGF- $\beta 1$ transfection). We observed that the expression was greater 72 hours post-transfection (Fig. 1A) and thus 72 hours was selected for the rest of our experiments. Also, DAPI staining was used to mark nuclei in this study in order to examine the number of apoptotic podocytes after exposure to TGF- $\beta 1$ for 72 hours with and without miR-155 knockdown. In this report, we did not provide data demonstrating a counterstaining for GFP and DAPI (i.e., to mark nuclei in Fig. 1A). It would be a good addition to the whole study if the counterstaining was performed.

\section{Conclusions}

Upregulation of TGF- $\beta 1$ and caspase- 9 leads to apoptosis of podocyte. This process also impairs the protein expression of nephrin and amplifies expression of desmin. Results of the present study demonstrated that knockdown of miR-155 alleviates these changes in podocytes. The data suggest that miR-155 plays an important role in mediating podocyte injury induced by TGF- $\beta 1$ and that nephrin and desimin are necessary to be engaged in the role of miR-155. Our results further indicate that inhibition of miR-155 signal pathways has a protective effect on podocyte injury. Targeting one or more of these signaling molecules may present new opportunities for treatment and management of podocyte injury observed in glomerulonephritis.

\section{Grant Support}

The Natural Science Foundation of Guangxi (No.2014GXNSFAA118269 and Scientific Research and Technical Exploitation of Baise (BK20160608)). 


\section{Cellular Physiology Cell Physiol Biochem 2017;42:1469-1480 \begin{tabular}{ll|l} 
DOI: 10.1159/000479211 & $\begin{array}{l}\text { O 2017 The Author(s). Published by S. Karger AG, Basel } \\
\text { www.karger.com/cpb }\end{array}$ \\
\cline { 2 - 4 }
\end{tabular}}

Lin et al.: MiR-155 Signaling and Podocyte Injury

\section{Disclosure Statement}

None.

\section{References}

$>1$

Duffield JS: Cellular and molecular mechanisms in kidney fibrosis. J Clin Invest 124:2299-2306. Sweetwyne MT, Tao J, Susztak K: Kick it up a notch: Notch signaling and kidney fibrosis. Kidney Int Suppl (2011) 2014;4:91-96.

Schnaper HW: Renal fibrosis. Methods Mol Med 2005;117:45-68.

Lee VW, Harris DC: Adriamycin nephropathy: A model of focal segmental glomerulosclerosis. Nephrology 2011;16:30-38.

Ghadami M, Makita Y, Yoshida K, Nishimura G, Fukushima Y, Wakui K, Ikegawa S, Yamada K, Kondo S, Niikawa N, Tomita H: Genetic mapping of the Camurati-Engelmann disease locus to chromosome 19q13.1-q13.3. Am J Hum Genet 2000;66:143-147.

Vaughn SP, Broussard S, Hall CR, Scott A, Blanton SH, Milunsky JM, Hecht JT: Confirmation of the Mapping of the Camurati-Englemann Locus to 19q13.2 and Refinement to a 3.2-cM Region. Genomics 2000;66:119121.

and JJL, Roberts AB: Regulation of immune responses by TGF- $\beta$. Annu Rev Immunol 1998;16:137-161. Oh SP, Seki T, Goss KA, Imamura T, Yi Y, Donahoe PK, Li L, Miyazono K, ten Dijke P, Kim S, Li E: Activin receptor-like kinase 1 modulates transforming growth factor- $\beta 1$ signaling in the regulation of angiogenesis. Proc Natl Acad Sci USA 2000;97:2626-2631.

Wahl SM, Wen J, Moutsopoulos N: TGF- $\beta$ : a mobile purveyor of immune privilege. Immunol Rev 2006;213:213-227.

Lee HS, Song CY: Effects of TGF-beta on podocyte growth and disease progression in proliferative podocytopathies. Kidney Blood Press Res 2010;33:24-29.

Kim TS, Kim JY, Hong HK, Lee HS: mRNA expression of glomerular basement membrane proteins and TGFbeta1 in human membranous nephropathy. J Pathol 1999;189:425-430.

Patek CE, Fleming S, Miles CG, Bellamy CO, Ladomery M, Spraggon L, Mullins J, Hastie ND, Hooper ML: Murine Denys-Drash syndrome: evidence of podocyte de-differentiation and systemic mediation of glomerulosclerosis. Hum Mol Genet 2003;12:2379-2394.

Schnaper HW, Jandeska S, Runyan CE, Hubchak SC, Basu RK, Curley JF, Smith RD, Hayashida T: TGF-beta signal transduction in chronic kidney disease. Front Biosci (Landmark Ed) 2009;14:2448-2465. Wynn TA: Cellular and molecular mechanisms of fibrosis. J Pathol 2008;214:199-210.

Muller-Deile J, Gellrich F, Schenk H, Schroder P, Nystrom J, Lorenzen J, Haller H, Schiffer M: Overexpression of TGF-beta Inducible microRNA-143 in Zebrafish Leads to Impairment of the Glomerular Filtration Barrier by Targeting Proteoglycans. Cell Physiol Biochem 2016;40:819-830.

Massague J, Blain SW, Lo RS: TGFbeta signaling in growth control, cancer, and heritable disorders. Cell 2000;103:295-309.

Sanz AB, Sanchez-Nino MD, Ramos AM, Moreno JA, Santamaria B, Ruiz-Ortega M, Egido J, Ortiz A: NFkappaB in renal inflammation. J Am Soc Nephrol 2010;21:1254-1262.

Schiffer M, Mundel P, Shaw AS, Bottinger EP: A novel role for the adaptor molecule CD2-associated protein in transforming growth factor-beta-induced apoptosis. J Biol Chem 2004;279:37004-37012.

Huang H, You Y, Lin X, Tang C, Gu X, Huang M, Qin Y, Tan J, Huang F: Inhibition of TRPC6 Signal Pathway Alleviates Podocyte Injury Induced by TGF-beta1. Cell Physiol Biochem 2017;41:163-172.

Faraoni I, Antonetti FR, Cardone J, Bonmassar E: miR-155 gene: a typical multifunctional microRNA. Biochim Biophys Acta 2009;1792:497-505.

Calame K: MicroRNA-155 function in B Cells. Immunity 2007;27:825-827.

Elton TS, Selemon H, Elton SM, Parinandi NL: Regulation of the MIR155 host gene in physiological and pathological processes. Gene 2013;532:1-12.

O'Connell RM, Rao DS, Baltimore D: microRNA regulation of inflammatory responses. Annu Rev Immunol 2012;30:295-312. 


\section{Cellular Physiology Cell Physiol Biochem 2017;42:1469-1480 \begin{tabular}{l|l} 
DOI: 10.1159/000479211 & $\begin{array}{l}\text { O 2017 The Author(s). Published by S. Karger AG, Basel } \\
\text { www.karger.com/cpb }\end{array}$ \\
\hline
\end{tabular}}

Lin et al.: MiR-155 Signaling and Podocyte Injury

-24 Sonkoly E, Janson P, Majuri ML, Savinko T, Fyhrquist N, Eidsmo L, Xu N, Meisgen F, Wei T, Bradley M, Stenvang J, Kauppinen S, Alenius H, Lauerma A, Homey B, Winqvist O, Stahle M, Pivarcsi A: MiR-155 is overexpressed in patients with atopic dermatitis and modulates T-cell proliferative responses by targeting cytotoxic T lymphocyte-associated antigen 4. J Allergy Clin Immunol 2010;126:581-589.e581-520.

25 Moore CS, Rao VT, Durafourt BA, Bedell BJ, Ludwin SK, Bar-Or A, Antel JP: miR-155 as a multiple sclerosisrelevant regulator of myeloid cell polarization. Ann Neurol 2013;74:709-720.

26 Lin X, You Y, Wang J, Qin Y, Huang P, Yang F: MicroRNA-155 deficiency promotes nephrin acetylation and attenuates renal damage in hyperglycemia-induced nephropathy. Inflammation 2015;38:546-554.

-27 Wang G, Kwan BC, Lai FM, Chow KM, Li PK, Szeto CC: Elevated levels of miR-146a and miR-155 in kidney biopsy and urine from patients with IgA nephropathy. Dis Markers 2011;30:171-179.

-28 Huang Y, Liu Y, Li L, Su B, Yang L, Fan W, Yin Q, Chen L, Cui T, Zhang J, Lu Y, Cheng J, Fu P, Liu F: Involvement of inflammation-related miR-155 and miR-146a in diabetic nephropathy: implications for glomerular endothelial injury. BMC Nephrol 2014;15:142.

29 Krebs CF, Kapffer S, Paust HJ, Schmidt T, Bennstein SB, Peters A, Stege G, Brix SR, Meyer-Schwesinger C, Muller RU, Turner JE, Steinmetz OM, Wolf G, Stahl RA, Panzer U: MicroRNA-155 drives TH17 immune response and tissue injury in experimental crescentic GN. J Am Soc Nephrol 2013;24:1955-1965.

30 Song L, Shi S, Jiang W, Liu X, He Y: Protective role of propofol on the kidney during early unilateral ureteral obstruction through inhibition of epithelial-mesenchymal transition. Am J Transl Res 2016;8:460-472.

31 Wu H, Huang T, Ying L, Han C, Li D, Xu Y, Zhang M, Mou S, Dong Z: MiR-155 is Involved in Renal IschemiaReperfusion Injury via Direct Targeting of FoxO3a and Regulating Renal Tubular Cell Pyroptosis. Cell Physiol Biochem 2016;40:1692-1705.

-32 Wan YG, Che XY, Sun W, Huang YR, Meng XJ, Chen HL, Shi XM, Tu Y, Wu W, Liu YL: Low-dose of multiglycoside of Tripterygium wilfordii Hook. f., a natural regulator of TGF-beta1/Smad signaling activity improves adriamycin-induced glomerulosclerosis in vivo. J Ethnopharmacol 2014;151:1079-1089.

-33 Saikumar J, Hoffmann D, Kim TM, Gonzalez VR, Zhang Q Goering PL, Brown RP, Bijol V, Park PJ, Waikar SS, Vaidya VS: Expression, circulation, and excretion profile of microRNA-21, -155, and -18a following acute kidney injury. Toxicol Sci 2012;129:256-267.

-34 Lu J, Kwan BC, Lai FM, Tam LS, Li EK, Chow KM, Wang G, Li PK, Szeto CC: Glomerular and tubulointerstitial miR-638, miR-198 and miR-146a expression in lupus nephritis. Nephrology (Carlton) 2012;17:346-351.

35 Thai TH, Patterson HC, Pham DH, Kis-Toth K, Kaminski DA, Tsokos GC: Deletion of microRNA-155 reduces autoantibody responses and alleviates lupus-like disease in the Fas(lpr) mouse. Proc Natl Acad Sci USA 2013;110:20194-20199.

-36 Li J, Campanale NV, Liang RJ, Deane JA, Bertram JF, Ricardo SD: Inhibition of p38 mitogen-activated protein kinase and transforming growth factor-beta1/Smad signaling pathways modulates the development of fibrosis in adriamycin-induced nephropathy. Am J Pathol 2006;169:1527-1540.

-37 Liu Y, Su L, Lin Q, Han Y, You P, Fan Q: Induction of C-Mip by IL-17 Plays an Important Role in AdriamycinInduced Podocyte Damage. Cell Physiol Biochem 2015;36:1274-1290.

38 Zhang HT, Wang WW, Ren LH, Zhao XX, Wang ZH, Zhuang DL, Bai YN: The mTORC2/Akt/NFkappaB Pathway-Mediated Activation of TRPC6 Participates in Adriamycin-Induced Podocyte Apoptosis. Cell Physiol Biochem 2016;40:1079-1093.

39 Lee HS, Song CY: Differential role of mesangial cells and podocytes in TGF-beta-induced mesangial matrix synthesis in chronic glomerular disease. Histol Histopathol 2009;24:901-908.

$>40$ Dessapt C, Baradez MO, Hayward A, Dei Cas A, Thomas SM, Viberti G, Gnudi L: Mechanical forces and TGFbeta1 reduce podocyte adhesion through alpha3beta1 integrin downregulation. Nephrol Dial Transplant 2009;24:2645-2655.

41 Kopp JB, Factor VM, Mozes M, Nagy P, Sanderson N, Bottinger EP, Klotman PE, Thorgeirsson SS: Transgenic mice with increased plasma levels of TGF-beta 1 develop progressive renal disease. Lab Invest 1996;74:991-1003.

42 Sanderson N, Factor V, Nagy P, Kopp J, Kondaiah P, Wakefield L, Roberts AB, Sporn MB, Thorgeirsson SS: Hepatic expression of mature transforming growth factor beta 1 in transgenic mice results in multiple tissue lesions. Proc Natl Acad Sci USA 1995;92:2572-2576.

-43 Schiffer M, Bitzer M, Roberts IS, Kopp JB, ten Dijke P, Mundel P, Bottinger EP: Apoptosis in podocytes induced by TGF-beta and Smad7. J Clin Invest 2001;108:807-816. 


\section{Cellular Physiology Cell Physiol Biochem 2017;42:1469-1480

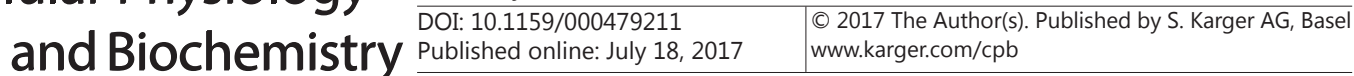 \\ Lin et al.: MiR-155 Signaling and Podocyte Injury}

44 Huber TB, Kottgen M, Schilling B, Walz G, Benzing T: Interaction with podocin facilitates nephrin signaling. J Biol Chem 2001;276:41543-41546.

45 Lehtonen S, Lehtonen E, Kudlicka K, Holthöfer H, Farquhar MG: Nephrin Forms a Complex with Adherens Junction Proteins and CASK in Podocytes and in Madin-Darby Canine Kidney Cells Expressing Nephrin. Am J Pathol 165:923-936.

46 Yuan H, Takeuchi E, Salant DJ: Podocyte slit-diaphragm protein nephrin is linked to the actin cytoskeleton. Am J Physiol Renal Physiol 2002;282:F585-591.

-47 Wagner N, Morrison H, Pagnotta S, Michiels J-F, Schwab Y, Tryggvason K, Schedl A, Wagner K-D: The podocyte protein nephrin is required for cardiac vessel formation. Hum Mol Genet 2011;20:2182-2194.

-48 Perez-Hernandez J, Olivares MD, Forner MJ, Chaves FJ, Cortes R, Redon J: Urinary dedifferentiated podocytes as a non-invasive biomarker of lupus nephritis. Nephrol Dial Transplant DOI:10.1093/ndt/ gfw002.

49 Jeong KH, Asanuma K, Lydia A, Takagi M, Asao R, Kodama F, Asanuma E, Tomino Y: Combination therapy with telmisartan and oxacalcitriol suppresses the progression of murine adriamycin nephropathy. Nephron 2015;129:143-154.

50 Li X, Chuang PY, D'Agati VD, Dai Y, Yacoub R, Fu J, Xu J, Taku O, Premsrirut PK, Holzman LB, He JC: Nephrin Preserves Podocyte Viability and Glomerular Structure and Function in Adult Kidneys. J Am Soc Nephrol 2015;26:2361-2377.

51 Yang H, Wang Q, Li S: MicroRNA-218 promotes high glucose-induced apoptosis in podocytes by targeting heme oxygenase-1. Biochem Biophys Res Commun 2016;471:582-588.

-52 Yu J, Gong W, Wu Y, Li S, Cui Y, Ma Y, Zhang Y, Yang G, Huang S, Jia Z, Zhang A: mPGES-1-derived PGE2 contributes to adriamycin-induced podocyte injury. Am J Physiol Renal Physiol 2016;310:F492-498.

-53 Bär H, Strelkov SV, Sjöberg G, Aebi U, Herrmann H: The biology of desmin filaments: how do mutations affect their structure, assembly, and organisation? J Struct Biol 2004;148:137-152.

54 Paulin D, Li Z: Desmin: a major intermediate filament protein essential for the structural integrity and function of muscle. Exp Cell Res 2004;301:1-7.

55 Shah SB, Davis J, Weisleder N, Kostavassili I, McCulloch AD, Ralston E, Capetanaki Y, Lieber RL: Structural and Functional Roles of Desmin in Mouse Skeletal Muscle during Passive Deformation. Biophys J 2004;86:2993-3008.

56 Heling A, Zimmermann R, Kostin S, Maeno Y, Hein S, Devaux B, Bauer E, Klovekorn WP, Schlepper M, Schaper W, Schaper J: Increased expression of cytoskeletal, linkage, and extracellular proteins in failing human myocardium. Circ Res 2000;86:846-853.

57 Kakimoto T, Okada K, Hirohashi Y, Relator R, Kawai M, Iguchi T, Fujitaka K, Nishio M, Kato T, Fukunari A, Utsumi H: Automated image analysis of a glomerular injury marker desmin in spontaneously diabetic Torii rats treated with losartan. J Endocrinol 2014;222:43-51.

58 Floege J, Kriz W, Schulze M, Susani M, Kerjaschki D, Mooney A, Couser WG, Koch KM: Basic fibroblast growth factor augments podocyte injury and induces glomerulosclerosis in rats with experimental membranous nephropathy. J Clin Invest 1995;96:2809-2819.

59 Zhang C, Hu JJ, Xia M, Boini KM, Brimson C, Li PL: Redox signaling via lipid raft clustering in homocysteineinduced injury of podocytes. Biochim Biophys Acta 2010;1803:482-491.

60 Eto N, Wada T, Inagi R, Takano H, Shimizu A, Kato H, Kurihara H, Kawachi H, Shankland SJ, Fujita T, Nangaku M: Podocyte protection by darbepoetin: preservation of the cytoskeleton and nephrin expression. Kidney Int 2007; 72:455-463.

61 Huang F, Wang Q Ma X, Wu L, Guo F, Qin G: Valsartan inhibits amylin-induced podocyte damage. Microvasc Res 2016;106:101-109.

62 Zuo Y, Yang HC, Potthoff SA, Najafian B, Kon V, Ma LJ, Fogo AB: Protective effects of PPARgamma agonist in acute nephrotic syndrome. Nephrol Dial Transplant 2012;27:174-181. 